\title{
EL GRADO CERO DE LA COMUNICACIÓN
}

\section{COMMUNICACTION DEGREE ZERO}

\section{FERNANDO ALBÁN ${ }^{1}$}

Recibido: 31 de enero de 2017

Aceptado: 6 de marzo de 2017

\footnotetext{
${ }^{1}$ Pontificia Universidad Católica del Ecuador, Facultad de Comunicación y Lingüística y Literatura, Escuela de Comunicación, Ecuador (FPALBAN @puce.edu.ec).
} 



\title{
EL GRADO CERO DE LA COMUNICACIÓN
}

\section{COMMUNICACTION DEGREE ZERO}

\author{
FERNANDO ALBÁN
}

PALABRAS CALVE: comunicación, cultura, política, función poética, función metalingüística

KEY WORDS: communcation, culture, politics, poetic function, metalinguistic function

\section{RESUMEN $^{1}$}

Bolívar Echeverría en su texto Definición de la Cultura se propone establecer un vínculo entre el sistema de la producción social desarrollado por Marx y el esquema de la comunicación propuesto por Jakobson. La búsqueda de ese vínculo, en último término, es, para Echeverría, la forma en que la política se convierte en elemento esencial de la dimensión cultural. En el presente artículo, se busca establecer una aproximación crítica a esta problemática, pues Echeverría ubica lo político en la línea de tensión que va de la función expresiva a la apelativa, pasando por la referencial, y deja de lado las funciones metalingüística y poética: ámbito privativamente humano de la comunicación. Esto se debe a que Echeverría parte del modelo de la comunicación oral ideal, la que sucede en presencia de los interlocutores. Es necesario, por lo tanto, evidenciar el vínculo entre lo político y lo fático-poético para entender cómo el ámbito de lo político es esencial en la conformación de la cultura, de lo humano.

\footnotetext{
${ }^{1}$ En el presente texto, todas las traducciones del francés son hechas por el autor de este artículo.
} 


\begin{abstract}
The present work establishes the relationship between the linguistic, the theory of Jakobson and the book of Bolivar Echeverria, Definición de la Cultura. In fact, Echeverría sets out the un link between the production of a marxist with the communication model of Jakobson. The political aspect is still the focus point in the society according to Bolívar Echeverría. Therefore, this article tries to distinguish and establish a solution between the political perception of

Bolívar Echeverría and the relationship with the communication model of Jakobson. Therefore, the analysis is carried out of the metalinguistics and poetic. On the other hand, for Bolívar Echeverría, the perception of the communication remains essentially oral. However, it is important connect politics and poetic, to understand politic as a component of society of the culture, and as a result, understand the human being.
\end{abstract}

\title{
INTRODUCCIÓN
}

En el texto Definición de la Cultura, "transcripción corregida" de un curso impartido por Bolívar Echeverría en la Facultad de Filosofía y Letras de la UNAM, se afirma que: "Es el carácter 'político' del animal humano lo que hace de él, inmediatamente, un ser 'semiótico'" (Echeverría, 2001: p. 83). La referencia a la Política de Aristóteles en este, como en muchos otros fragmentos del texto de Echeverría, es innegable. Para el filósofo griego, referente ineludible en la construcción del pensamiento occidental sobre la política, la condición política del animal humano es indisociable de su ser semiótico y, de manera más específica, de su ser semiótico lingüístico:
La razón por la cual el hombre es un animal político, más que la abeja y que cualquier otro animal gregario, es evidente. En efecto, tal como decimos, la naturaleza no hace nada en vano. El hombre, por cierto, es el único de los animales que posee palabra. Porque la voz es signo del dolor y del placer, y por eso la poseen también los demás animales (pues su naturaleza ha llegado al punto de poseer sensación de lo doloroso y de lo placentero y de poder manifestársela unos a otros), pero la palabra tiene por fin expresar lo ventajoso y lo perjudicial, y por ello también lo justo y lo injusto. En efecto, propio y exclu- 
sivo de los hombres respecto de los demás animales es el que sólo ellos tienen la percepción de lo bueno y de lo malo, de lo justo y de lo injusto y de lo demás por el estilo, y es la comunidad de quienes tienen tales percepciones la que constituye una casa y una ciudad (Aristóteles, 2005: p. 57-58).

La voz es la marca que ata al animal a la inmediatez de la satisfacción natural, mientras que la palabra, que es privativa del humano, marca la posibilidad del diseño de un proyecto tendiente a la modificación permanente de los humanos, en función del discernimiento del mejor de los mundos. La politicidad en el humano radica, justamente, en términos de Bolívar Echeverría, en que "la insatisfacción orgánica se ha convertido en el soporte de un descontento 'político'" (2001: p. 82). Descontento que le concierne a su figura presente $y$, con ello, a la necesaria reinvención de su identidad.

En la fase productiva, el sujeto humano proyecta convertirse a sí mismo en alguien diferente, adquirir otra forma; después, en la fase consuntiva, al asumir dicha forma, lleva a cabo ese proyecto. Podría decirse que, en virtud de este hiato que ha roto el continuum natural de las dos fases reproductivas animales, el ser humano desdobla su condición doble y existe en dos versiones de sí mismo. Podría decirse también que, por ello, entre esas dos versiones necesariamente aparece una tensión comunicativa, una tensión que se resuelve precisamente a través del objeto práctico (Echeverría, 2001, p. 82).

Pero, el ser cuya condición es la política produce y consume objetos cuyas formas entrañan necesariamente significaciones. El objeto práctico deviene, entonces, en objeto semiótico y el animal físico deviene en político o en meta-físico. La prevalencia de la forma sobre la sustancia, en el objeto forjado por la imaginación humana, deviene en fuente inagotable de sentido.

Hay unos objetos hacia un extremo, cuya capacidad de transmitir muestra un grado relativamente bajo de agilidad, de precisión o de ambas (pensemos en una casa, por ejemplo), mientras hay otros, hacia el extremo opuesto, en los que su capacidad de transmitir posee una de las características, o las dos, en un grado relativamente alto (pensemos en un guiño de ojos, por ejemplo). Los primeros serían aquellos objetos que presentan menos forma en más material, aquellos cuya materialidad es menos dúctil, más reacia a adop- 
tar una forma y cuyo ciclo productivo-consuntivo es más prolongado; los segundos a la inversa, serían aquellos objetos que en menos material tienen más forma, aquellos cuyo material es más sutil, más apto para asumir formas y cuyo tiempo de producción consumo es más corto (Echeverría, 2001: p. 98).

Entre estos últimos los signos verbales, que implican "transformaciones en el estado acústico de la atmósfera", son más aptos para la transmisión de información, pues se constituyen sobre un máximo de forma y un mínimo de materia. Así, la semiosis lingüística se muestra más efectiva a la hora de la comunicación que la semiosis práctica, que se establece en la producción y el consumo de objetos. En esta sucesión de relevos, que tienen como fin una optimización de la comunicación, la posibilidad última recae sobre el significante fónico del signo lingüístico. En esta escena, Bolívar Echeverría vincula su gesto con el de la tradición metafísica occidental, tradición des-construida por Jacques Derrida en su texto titulado: De la gramatología. En efecto, lo que ahí sostiene el filósofo francés es que el elemento estructurante -o el sedimento en el que se apoya sistemáticamente la racionalidad metafísica occidental- consiste en la alianza efectuada entre el logo-centrismo y el fono-centrismo; asociación que se efectúa a expensas de la represión del significante escrito. En adelante se tratará de establecer las consecuencias que se desprenden, en lo que se refiere al tema de la cultura y su vínculo con la comunicación, de la adscripción no crítica del discurso de Bolívar Echeverría a la tradición constituida por el logo-fono-centrismo.

\section{DISCUSIÓN}

Bolívar Echeverría pugnará, en Definición de la cultura, por enlazar el pensamiento de Marx sobre la producción social con la reflexión que Jakobson realiza sobre el proceso de la comunicación humana en su libro Ensayos de lingüística general. Echeverría, de ese modo, pretende apuntalar la tesis de que existe una relación de identidad entre el proceso de producción/consumo de objetos prácticos y el proceso de producción/ consumo de significaciones; correspondencia identitaria de la que parte, además, su definición de la cultura. Así, Echeverría sostiene, en proximidad con el pensamiento de Jakobson: 
Aparte de las cuatro funciones básicas del proceso de comunicación lingüística -que de manera aproximada podrían reconocerse también en la comunicación animal (recordemos lo que decía Marx: "La anatomía humana da la clave de la anatomía del mono")-, Jakobson distingue otras dos funciones que se afirman como exclusivas de la comunicación semiótica o humana: la función metalingüística y la función poética. La primera está centrada en torno al elemento llamado "código"y la segunda lo estaría en torno al elemento llamado "mensaje" (Echeverría, 2001: p. 92).

En la función metalingüística, propia del animal político, "el código no está encarnado en los agentes de la comunicación sino que entre quienes lo 'usan'y ese código hay un cierto distanciamiento, un decalage" (Echeverría, 2001: p. 95). La distancia que se suscita y preserva en el momento del acto comunicativo entre el código y sus usuarios es la condición para que se produzca una relación de no sujeción estricta al mismo; relación crítica que implica que el código lingüístico pueda y deba ser perfectible. La función metalingüística recuerda que a la vida humana le es inherente una "existencia en ruptura". Por el contrario, en la comunicación animal el código es una adherencia natural de la especie, lo que impide cualquier tentativa de volverse contra él, de infringirlo, de cuestionarlo. En términos freudianos la situación del código en la vida de los animales puede formularse de la siguiente manera:

¿Por qué nuestros parientes, los animales, no presentan semejante lucha cultural [entre Eros y muerte]? Pues no lo sabemos. Es muy probable que algunos, como las abejas, las hormigas y las termitas, hayan bregado durante milenios hasta alcanzar las organizaciones estatales, la distribución del trabajo, la limitación de la libertad individual que hoy admiramos en ellos. Nuestra presente situación cultural queda bien caracterizada por la circunstancia de que, según nos dicen nuestros sentimientos, no podríamos ser felices en ninguno de esos estados animales, ni en cualquiera de las funciones que allí se confieren al individuo. Puede ser que otras especies animales hayan alcanzado un equilibrio transitorio entre las influencias del mundo exterior y los instintos que se combaten mutuamente, produciéndose así una detención del desarrollo. Es posible que en el hombre primitivo un nuevo empuje de la libido haya renovado el impulso antagónico del instinto de destrucción" (Freud, 2010: p. 123). 
La función metalingüística es heredera directa de la pulsión de muerte sin la cual la vida humana carecería de movilidad, de autocrítica. Lo metalingüístico permite un distanciamiento del código, la posibilidad de observarlo en distancia, "por sobre" -condición de lo meta-; es decir, abre la posibilidad de modificarlo, incluso, en último término, de volverlo contra sí mismo: espacio de lo poético.

En cuanto a la función poética esta se determina, también, como una puesta en crisis del código, pues en la "composición y de-composición del mensaje" (Echeverría, 2001: p. 96) se abre la vía para la transgresión de la norma. Asimismo, la función poética bloquea el paso hacia el referente; este efecto, inherente a lo poético, se suscita en momentos en que se concentra toda la atención de los interlocutores en la composición del mensaje, es decir en la densidad material de las palabras y de sus relaciones mutuas. En el poema, se pierde de vista la función referencial o cognitiva de las palabras, pues la atención recae en la forma; lo referencial, en el espacio de lo poético, pasa, por tanto, a un segundo plano.
La visée (Einstellung) du message en tant que tel, l'accent mis sur le message pour son compte, est ce qui caractérise la fonction poétique du langage [...] Cette fonction, qui met en évidence le côté palpable des signes, approfondit par là même la dichotomie fondamentale des signes et des objets (Jakobson, 1963: p. 218)².

En la función poética del lenguaje las palabras hacen ostensible su cuerpo al punto de volver opaco el sentido y contrariar o distender el vínculo que se establece en la comunicación. "La suprématie de la fonction poétique sur la fonction référentielle n'oblitère pas la référence (la dénotation), mais la rend ambiguë. A un message à double sens correspondent un destinateur dédoublé, un destinataire dédoublé, et, de plus, un référence dédoublé" ${ }^{\prime 3}$ (Jakobson, 1963: pp. 238-239).

Al proseguir con la descripción del conjunto de las funciones comunicativas desarrollada por Jakobson, Bolívar Echeverría sostiene que el acto comunicativo "gira en torno al entrecruzamiento de dos líneas de tensión, cada una de

\footnotetext{
${ }^{2}$ La consideración (Einstellung) del mensaje en cuanto tal, el acento puesto sobre el mensaje por sí mismo, es lo que caracteriza la función poética del lenguaje [...] Esta función, que pone de relieve el lado palpable de los signos, profundiza de la misma manera la dicotomía de los signos y de los objetos.

${ }^{3}$ La supremacía de la función poética sobre la función referencial no oblitera la referencia (la denotación), sino que la vuelve ambigua. A un mensaje con doble sentido, corresponde un destinador desdoblado, un destinatario desdoblado, y, además, un referente desdoblado.
} 
las cuales intenta prevalecer sobre las otra: una que va de la función expresiva a la función apelativa, y otra que va de la función referencial o 'sémica' a la función metalingüística o 'metasémica"' (Echeverría, 2001: p. 100). Es importante observar que, en el esfuerzo por prevalecer, el primer intento corre a cuenta de la línea de tensión que va de la función expresiva a la función apelativa. Lo determinante en esta tensión tiene que ver con el proceso de "autorrealización" del sujeto humano; es decir, se trata de "un proceso en el que cierta intención del sujeto está plasmándose como modificación, sea de sí mismo en el futuro o de 'otro', en el plano de la reciprocidad" (Echeverría, 2001: p. 100). Ahora bien, lo importante de este señalamiento tiene que ver con el hecho de que en la relación intersubjetiva, trazada por la línea de tensión que va de la función expresiva a la apelativa, según Echeverría, se constituye el ámbito de "lo político". Sin embargo, no deja de sorprender, hasta cierto punto, este postulado, pues, como se señaló anteriormente, tanto la función expresiva como la apelativa no son exclusivas del mundo humano, sino que también forman parte de la comunicación animal. Entonces, ¿por qué razón Echeverría hace que la politicidad del humano dependa de la convergencia de la función expresiva y apelativa, dejando fuera de esta determinación a las funciones metalingüística y poética?
Para responder a esta pregunta, es importante señalar que la situación comunicativa que sustenta, tanto en Jakobson como en Echeverría, la descripción del conjunto de las funciones comunicativas -como también de su eventual jerarquización- es la copresencia del emisor y del receptor en el acto de la comunicación; copresencia que es sustancial a la comunicación de tipo oral. En la transmisión del signo oral, receptor y emisor se hallan el uno en presencia del otro, solo así la "expresión de una experiencia del mundo, hecha como una apelación al receptor para que se modifique, resulta ser el marco que delimita la referencia práctica general al exterior, al contexto. La función referencial lingüística o de tipo cognoscitivo, la producción del conocimiento, estaría así siempre dominada por la gravitación de lo expresivo-apelativo; estaría al servicio de la performance comunicativa propiamente dicha, del flujo vital y político que, al conjuntar al cifrador con el descifrador, promueve una 'voluntad de saber'"' (Echeverría, 2001: p. 101). Entonces, en la tensión que va de lo expresivo a lo apelativo, se anudan la voluntad de poder -ámbito en el que la intención del sujeto se plasma como modificación del "Otro" o de sí mismo-y la voluntad del saber -ámbito de humanización o de interiorización de lo "Otro" o de la "Naturaleza"-. 
Lo político tiene que ver, en Echeverría, con la transmisión de una cierta intención por parte del emisor que requiere, para ser eficaz, situar al receptor en el plano de la reciprocidad. En esta escena, el mensaje debe siempre llegar a su destino sin que, en el camino, la referencia se vuelva ambigua y, con ello, el emisor y el receptor pierdan su identidad o se pluralicen al desdoblarse; es decir, el canal por el que transita el signo debe, en cierto modo, anularse en la copresencia de los sujetos hablantes. Esta necesidad, impuesta por la elección del esquema de la oralidad como paradigma de la comunicación humana, contraviene lo señalado por Echeverría en múltiples pasajes de su texto, Definición de la cultura, en particular cuando se refiere a la función fática:

Se trata de una función que solo se muestra en su pureza cuando observamos la comunicación en el "grado cero" de sus posibilidades, en aquellos comportamientos comunicativos -como el saludo, por ejemplo- en los que todo el proceso se encuentra simplemente en hacer ostensible, en general, la posibilidad de la expresión y de la apelación, hacer patente la vigencia de la comunidad que existe entre el emisor y el receptor-comunidad que, como sabemos, tiene una consistencia doble: corporal, pues ambos comparten el mismo contacto, y mental, pues ambos comparten el mismo código (Echeverría, 2001: p. 91-92).

La función fática, en tanto condición de posibilidad de la expresión-apelación, inserta a la comunidad en el espacio de la relación que se establece entre el emisor y el receptor; de ahí que el elemento sobre el que recae la responsabilidad de la efectividad de la función haya sido denominado canal, contacto. La función fática es la encargada de vincular a los individuos entre sí, es por ello que el término viene "del griego fatis 'rumor del habla' y que remite a algo que 'no significa nada' pero que es dicho por todos y oído por todos" (Echeverría, 2001: p. 91). Y si consideramos que el elemento común a la colectividad es el código, entonces se produce la indisoluble alianza entre la función fática y la metalingüística, entre el contacto o canal y el código. El código es aquel componente que, en todo momento, convierte en cajas de resonancia a los participantes del acto comunicativo, como si fuese un rumor del habla o también "un rumor del aire", como si los interlocutores fuesen lo accesorio. "Rumor del habla" o "rumor del aire" son los términos que utiliza Echeverría para designar a la función fática. Código y canal son no solo lo que 
mantiene cohesionada a la comunidad, sino lo que la hace posible. La pregunta que se torna necesaria es ipor qué Echeverría sitúa lo político en la incidencia deliberada de un emisor sobre el comportamiento de un receptor y no lo hace recurriendo a las funciones que él mismo considera como privativas del humano y que tienen como propósito fundamental la producción de la comunidad? ${ }^{4}$

El canal o contacto, lo fático -que, en suma, es el entre- en tanto espacio que articula y separa a los participantes en el acto comunicativo es el mundo que insiste o que subsiste en toda relación comunicativa; en ese sentido, la política tiene que procurar incidir en la configuración del espacio-mundo más que en la tonalidad o sentido de la incidencia de un individuo sobre otro. Pero, ¿qué ocurre cuando el entre, el espacio que une y separa, es considerado a partir de las grandes distancias?

Basta volver la mirada hacia las grandes distancias para que aparezca, en semiología como en física, que el tiempo transcurrido entre la emisión y la recepción es la clave de todo el asunto, y que la situación en que el emisor y el receptor pueden consi- derarse como simultáneamente en presencia uno del otro tiene que describirse como un caso particular de la otra y no al revés. Toda la tendencia más reciente en teoría del discurso toma sin embargo la actitud contraria (a menudo tanto más cuanto más cree estar haciendo lo opuesto): intenta describir la significación que viene de las galaxias lejanas de la historia con esquemas sacados de la significación simultánea [...] La lingüística se encuentra pues en una especie de fase prerrelativista, en la que el signo (como la señal en la física tradicional) se propaga a través de un éter semiológico: durante su viaje al signo no le pasa nada, como si el tiempo-espacio bruscamente se borrase una vez producida la emisión, para reaparecer de nuevo del otro lado, una vez producida la recepción (Segovia, 1989: p. 176-177).

La subordinación de la función fática a la línea de tensión constituida por las funciones expresiva-apelativa equivale a la reducción del espacio-tiempo que se intercala entre los interlocutores del discurso para dar lugar a la presencia simultánea del emisor y del receptor; simultaneidad que es el ámbito propio

\footnotetext{
${ }^{4}$ Cabe recordar que tanto Jakobson como Echeverría coinciden en señalar que dentro de las funciones comunicativas aquellas que el humano comparte con el animal son: la expresiva, la apelativa y la referencial; mientras que son exclusivas del humano la metalingüística y la poética.
} 
de la producción de la idealidad: basta recordar la función del diálogo en la configuración platónica de la idealidad trascendental. En el ámbito ideal de la comunicación oral el espacio-tiempo por el que atraviesa el signo es desestimado, pues, allí donde la distancia parece extinguirse, la separación entre los interlocutores aparentemente no altera la trayectoria ni el sentido del mensaje. Por el contrario, si consideramos la comunicación escrita -en lugar de la oraltenemos que el signo escrito, al tener la misma consistencia material que el mundo por el cual circula, se produce necesariamente una recíproca modificación, pues el uno no es ajeno al otro. Solo de esta manera se puede entender a la función fática como rumor del habla que es, inmediatamente, rumor del mundo: el canal es el ruido 5 .

Supondríamos entonces que el sentido "viaja" en el "espacio" histórico como una onda "viaja" en el espacio físico. La onda física no es una cosa que está en el espacio y se mueve en él: es más bien ondulación de ese espacio mismo. En la macroestructura -una onda en el aire por ejemplo-, la onda no es otra materia (o energía) que traspasa la materia aérea: es ondulación del aire, es transmisión pura. La onda no "viaja" es el viaje. De modo paralelo, el sentido no es más que ondulación del "espacio" histórico, pero no está hecho de otra cosa que ese espacio histórico (Segovia, 1989: p. 177).

Ahora bien, si el signo altera el espacio por el que atraviesa y es, a su vez, alterado por este, entonces no cabe esperar que la intención que el mensaje vehicula quede intacta a la hora de la llegada a su destino. Es así que la función poética se anuda con la fática cuando adviene la ambigüedad o el doble sentido del mensaje y cuando, como efecto de aquello, se produce el desdoblamiento del emisor y del receptor. La función poética, señala Jakobson, hace del mensaje "una cosa que dura", le dota de espacio y, con ello, difiere o retarda su asimilación por parte del receptor, al punto de poner en riesgo la reciprocidad re-

\footnotetext{
${ }^{5}$ Los teóricos de la comunicación se proponen como objetivo fundamental la eliminación del ruido que es inherente a todo canal; esto se consigue, aparentemente, gracias al modelo de comunicación oral donde los interlocutores se encuentran en presencia. Así, cuando emisión y recepción son eventos cuasi-simultáneos se produce la ilusión de que el ruido se ha extinguido. Del otro lado, en la escritura, el mensaje debe transitar grandes distancias espacio-temporales; en este escenario de la comunicación, el ruido se incrementa con el tránsito que realiza la palabra en el dilatarse del entre. De ahí que el signo escrito no pueda eludir la ambigüedad.
} 
querida por la eficiencia comunicativa ${ }^{6}$. Justamente, la pérdida de la eficiencia productiva disfuncionaliza al mensaje y lo vuelve apto para ser indicador, según Echeverría, de la movilidad cultural. Es decir, la función poética pone en crisis el uso normativo del código e introduce, en la vida humana, la posibilidad de la crítica y, con ello, de la libertad. Bajo estas condiciones lo político supone lo poético y no, como señala Echeverría, el ajuste mediante la intención de las funciones emotiva y conativa. El humano es un animal político porque es poético.

Pues bien, un "habla" global del sujeto social, este hecho desde todo punto de vista inconcebible en el mundo de lo humano, es propio del mundo animal. En éste, cada una de las efectuaciones individuales del código es sólo un ejemplo singular de ejecución directa y "fiel" de las normas que están impresas en la consistencia biológica, instintiva, de cada uno de los ejemplares de la especie. El código del animal no es un código exteriorizado como institución sino integrado en esa consistencia y, en esa medida, absoluto (Echeverría, 2001: p. 152).

El distanciamiento, en el cual el código se mantiene con respecto a la ejecución individual del mismo, permite y promueve una relativa libertad de elección a la hora de la composición y descomposición del mensaje; más aún, esa libertad, en el momento de la elección, puede llegar al límite de atentar contra la intangibilidad del pacto convencional: transgredir la regla. En este sentido, lo poético radica en la posibilidad de romper con la reciprocidad comunicativa y, de esta manera, instaurar o reeditar un "comportamiento en ruptura". En el mundo humano, en oposición al mundo animal, el código no es absoluto, pues, en su ejecución, el humano trasciende los límites meramente funcionales que exigen el apego a la norma, y en esto consiste el sentido profundo de la acción poética?.

\footnotetext{
${ }^{6}$ Jacques Derrida, en su texto "Firma, acontecimiento y contexto", señala que la cualidad esencial de la escritura es la de encontrarse cercada por la ausencia: ausencia del emisor, pues el texto funciona más allá de la intencionalidad del autor, y también ausencia del receptor, pues se escribe siempre para un ausente. Al radicalizar el sentido de ausencia, mediante la escritura, el signo escrito debe exceder, siempre, todo destino y origen. Es así que la función poética se ejerce, en estricto sentido, en la escritura. La escritura es un vehículo sobre el cual la intencionalidad no ejerce poder; vehículo que transita sin la voluntad de sus pasajeros: es el "Barco ebrio" de Rimbaud.
}

${ }^{7}$ Resulta curioso que Bolívar Echeverría, el teórico del valor de uso, ubique lo político en el trayecto que va de la función emotiva a la apelativa, pasando por la referencial, pues lo que está en juego allí es la pura eficiencia -se ubica del lado de la producción-. Así, una política que ocurra en lo fático-poético es una política del disfrute improductivo: política afincada en la filia, en el amor (pasión sublimada). 


\section{CONCLUSIÓN}

Sartre, en su texto ¿Qué es la literatura?, rechaza cualquier posibilidad de considerar a la poesía como arte comprometido. Y esto precisamente porque, en el poema, el lenguaje no es el resultado de un uso convencional del código. Por esta razón el poema no tiene como finalidad fundamental la de comunicar un sentido intencional. En el uso poético del código, la palabra es materia indócil que se resiste a servir de reflejo fiel del autor; el poeta no puede mirarse en el poema. Por el contrario, "pour le poète, le langage est une structure du monde extérieur"8 (Sartre, 1948: p. 19). En el poema, las palabras se convierten en cosas u objetos, pues el mundo sucede en ellas sin seguir intencionalidad alguna. Pero si la poesía es apolítica, la prosa es, por el uso específico que en ella se hace del lenguaje, según Sartre, el único arte comprometido.

La prose est utilitaire par essence; je définirais volontiers le prosateur comme un homme que se sert des mots [...] L'art de la prose s'exerce sur le discours, sa matière est naturellement signifiante: c'est-à-dire que les mots ne sont pas d'abord des objets, mais des désignations d'objets (Sartre, 1948: p. 26) ${ }^{9}$.

En el poema, las palabras hacen ostensible su propia corporalidad, mientras que en la prosa lo que prima es la función referencial del mensaje subordinada a la línea de tensión entre lo expresivo y lo apelativo: "L'écrivain est un parleur: il désigne, démontre, ordonne, refuse, interpelle, supplie, insulte, persuade, insinue"10 (Sartre, 1948: p. 26). En los límites trazados por la reflexión sartreana, a propósito del arte comprometido, el sentido de la política se cristaliza en torno del llamado a la libertad de expresión; llamado que circunscribe lo político en un ámbito de tipo liberal-humanista, pues la política liberal se funda en la intencionalidad consciente del sujeto hablante y en los efectos que este es capaz de producir en sus interlocutores. Por el contrario, una política que brota de lo poético apela a la modificación y

\footnotetext{
${ }^{8}$ Para el poeta, el lenguaje es una estructura del mundo exterior.

${ }^{9}$ La prosa es utilitaria por esencia; definiría de buena gana al prosista como un hombre que se sirve de las palabras [...] El arte de la prosa se ejerce sobre el discurso, su materia es naturalmente significante: es decir que las palabras no son en primer lugar objetos, sino unas designaciones de objetos.

${ }^{10}$ El escritor es un hablante: él designa, demuestra, ordena, rechaza, interpela, suplica, insulta, persuade, insinúa.
} 
cuidado del mundo, espacio por donde circula el signo, pues la política poética no está centrada en el sujeto hablante. Como se puede constatar, la adscripción de Bolívar Echeverría -en el caso específico de la reflexión sobre la comunicación humana- a un sentido sartreano de la política -subjetivista/voluntarista- implica la adopción del modelo ejemplar de la comunicación oral.

En efecto, entre el habla y la lengua o entre el acto y el código, Echeverría opta, coincidiendo, en este punto, con Sartre, por el acto; es decir, por la "performance comunicativa"y política en la que una voluntad de saber se anuda a una voluntad de poder. En contraste con el sentido del productivismo comunicacional, la función fática solo se muestra de manera pura en aquellas interjecciones o gestos que ponen a prueba la apertura del canal y que remiten a algo que está en el límite de la significación.
Basta un mínimo gesto para preservar la distancia del entre, la disponibilidad del espacio por el que cada vez un mundo se insinúa: espacio común propicio para el reparto colectivo. En el relato de Kafka "Informe para una academia", Pedro el rojo, un simio que fue atrapado y encerrado en una jaula, al proferir la interjección "ihola!" es arrojado al ámbito de lo humano; el saludo, espacio fático, le abre la posibilidad de una experiencia recíproca, pero los marinos, destinatarios de esta verificación del canal, no responden al Ilamado y el contacto queda inconcluso. Apenas un leve contacto basta para que un signo sea lanzado al infinito de la no reciprocidad, pues el saludo dirigido por el simio no encuentra respuesta entre los humanos. En la interjección "hola", que significa todo y nada a la vez, pues brota como posibilidad, se cristaliza el sentido poético del lenguaje; es decir, el "grado cero" de la comunicación. 


\section{BIBLIOGRAFÍA}

Derrida, J. (1967) De la grammatologie. París: Les Éditions de Minuit.

Derrida, J. (1989) Márgenes de la filosofía. Madrid, España: Cátedra.

Echeverría, B. (2001) Definición de la cultura. México: Editorial Itaca.

Freud, S. (2010) El malestar en la cultura y otros ensayos. Madrid: Alianza Editorial.

Jakobson, R. (1963) Essais de linguistique générale 1. Les fondations du langage. París: Les Éditions de Minuit.

Kafka, F. (1990) Bestiario. Barcelona: Editorial Anagrama, S.A.

Sartre, J. P. (1948) Qu'est-ce que la littérature? Francia: Éditions Gallimard.

Segovia, T. (1989) Poética y profética. México, D. F: Fondo de Cultura Económica, S. A. 